Ravesteyn, P., Batenburg, R. Surveying the critical success factors of BPM-systems implementation. Business Process Management Journal: 2010, 16(3), 492-507

\begin{tabular}{|l|l|}
\hline $\begin{array}{l}\text { Postprint Version } \\
\text { Journal website }\end{array}$ & $\begin{array}{l}1.0 \\
\text { http://www.emeraldinsight.com/journals.htm?articleid=1864115\&show=abstrac }\end{array}$ \\
\hline Pubmed link & $\underline{ }$ \\
\hline DOI & $10.1108 / 1463715101104967$ \\
\hline
\end{tabular}

This is a NIVEL certified Post Print, more info at http://www.nivel.eu

\title{
Surveying the critical success factors of BPM-systems implementation
}

\author{
PASCAL RAVESTEYN, RESEARCH CENTRE FOR PROCESS INNOVATION, UNIVERSITY OF APPLIED SCIENCES \\ UTRECHT, UTRECHT, THE NETHERLANDS
}

RONALD BATENBURG, INSTITUTE OF INFORMATION AND COMPUTING SCIENCES, UTRECHT UNIVERSITY, UTRECHT, THE NETHERLANDS

\begin{abstract}
Purpose - The purpose of this paper is to explore if there is a common ground for the definition of business process management (BPM) and BPM-systems, as well as the critical success factors (CSFs) for BPM-system implementation. A BPM-system implementation framework is validated that classifies the CSFs in distinctive domains that can be used for BPM project management and organization.

Design/methodology/approach - A meta-analysis of literature was performed to develop a set of statements with regard to the definition, benefits and CSFs of BPM(-system) implementation. Then a survey was conducted among 39 Dutch consultants, developers and end-users of BPM-systems that vary in BPM experience. Through a web-questionnaire, the shared view of the respondents was measured with respect to the definition, benefits and the BPM-system implementation framework.

Findings - It appears that different respondent groups share a common view on the definition and benefits of BPM and BPM-systems, regardless their role in the value chain of BPM deployment within organizations. In addition, there is consensus on the CSFs of BPM-system implementation. In particular, it is supported that communication, involvement of stakeholders and governance is critical. Hence, organizations should realize that BPM-system implementation is not mainly an IT-project, but should preferably be initiated by top management.

Research limitations/implications - This paper is limited to representatives from Dutch organizations. Future research can be done in other countries to explore if BPM-systems and its CSFs differ across regions and cultures. Furthermore, the BPM-system implementation framework can be specifically validated by (comparative) case study or project research.

Originality/value - While BPM is commonly accepted as a concept, the CSFs for BPMsystem implementation is hardly validated. This paper shows, by empirical validation, if these CSFs from literature are supported by different groups of professionals. Furthermore, the CSFs for implementing BPM are modeled and classified in a framework build up from five areas. Analysis of the internal coherence of different survey items sets, supports that the authors can define the goals and CSFs when implementing BPM-systems.
\end{abstract}




\section{INTRODUCTION}

While business process management (BPM) has achieved a certain standing among both academic and practitioners as a management concept, the knowledge about IS/IT (i.e. BPM-systems) to support the implementation of BPM is still premature. Since several years BPM-systems - and software that enable BPM by using the service-oriented architecture (SOA) paradigm - is getting more attention (Hill et al., 2006). Since Smith and Fingar published their seminal book Business Process Management: The Third Wave a rise in both scientific and professional publications on BPM-systems has taken place (Smith and Fingar, 2003). In addition, a growing number of software developers and consultants enter the domain by providing their products and services for BPM-systems.

BPM-systems are the typical result of developments in both the business and IT-domain (Ravesteyn, 2007b). The most important influences from the business domain are total quality management (TQM) and business process reengineering (BPR) (Deming, 1982; Hammer and Champy, 2001). At the IT-domain different types of IS/IT influenced BPM-systems as it is currently used, like enterprise resource planning (ERP) systems, workflow management (WFM) systems (van der Aalst et al., 2003), advanced planning systems and more. Along with this general development, BPM started as the automation of a company's internal processes and then became more externally oriented towards the digitization of supply chains (Davis and Spekman, 2003). Obviously, one of the basic conditions for this has been the explosive development of internet technology and applications, the associated network standardization, and a significant change towards web services orientation.

Presently, BPM-systems are sometimes regarded "just another" software application, while others consider it as the basis for a new paradigm (Ravesteyn, 2007b). As a consequence, there is not a lot of scientific work available on the underlying architecture of a business process management systems (BPMS). The most apprehensive work has been done by Shaw et al. (2007) whom propose a pyramid architecture based on two legs. The first is the subject that is modeled while the second is the relating information system. Related to this distinction is the question whether the process of selection and implementation of BPM-systems can be done using available implementation methodologies and techniques, or that a new or adjusted method is needed as is concluded in Ravesteyn (2007a). Quite remarkable, most IT vendors and resellers seem to neglect the specific implementation aspects of BPMsystems as they tend to use existing software development methodologies and project management principles during BPM-implementations. Hence, the implementation of a BPM-systems is mainly regarded as a standard software development project (Krafzig et al., 2004). Standard software development methodologies however - such as the waterfall method, rapid application development or rational unified process - ignore the business or organizational aspects.

These are aspects of particular importance for BPM-system implementations as it implies deep and enterprise-wide process analyses, and the inclusion of process performance measurement for continuous process (quality) monitoring and improvement. Also, contributions to academic and professional journals are more focused on what the BPM concepts is, and why organizations start BPM-projects (van der Aalst et al., 2003; Fremantle et al., 2002; Karagiannis, 1995; Weske et al., 2004). While there is research on the maturity level of organizations that are using BPM (Rosemann et al., 2004; Harmon, 2004; Rosemann and de Bruin, 2005; Lee, J., et al., 2007; Hammer, 2007), the question how a BPM-system can be implemented, and what business value it can bring, continues to be a white-spot. Next to this, the number of quantitative research available on BPM implementation is very limited. For example, of all the articles in the Business Process Management Journal between 2000 and 2007, there are only 33 articles that are based on a quantitative research methodology and of these articles, three are about business process implementation (Wells, 2000; Al-Mashari et al., 2001; Davenport et al., 2004) while seven articles are slightly related to this topic (Woon, 2000; Osuagwu, 2002; Crowe et al., 2002; Kim et al., 2005; Bhatt and Trout, 2005; Mansar and Reijers, 2007; Lee, C., et al., 2007).

As the number of completed BPM-systems implementations in organizations is rather scarce, we decided to execute a consultation among BPM-practitioners in The Netherlands. In this paper, we present the results of a survey among three main parties that represent the supply or value chain of the deployment of BPMsystems. We first consulted a group of developers of BPM-systems, second, a group of BPM-implementers and finally end-users of BPM-systems. All three groups were questioned in a similar vein to investigate if there is a common understanding on:

1. What is BPM and what are BPM-systems? 
Ravesteyn, P., Batenburg, R. Surveying the critical success factors of BPM-systems implementation. Business Process Management Journal: 2010, 16(3), 492-507

2. What are critical success factors (CSFs) for implementing BPM-systems?

In the next section, the details on research methodology and the survey are presented, followed by a section with the results. Following a typical inductive approach, we subsequently describe from these results a framework for BPM-system implementation. We end with conclusions and some discussion and future research.

\section{Research methodology}

In 2007, a survey has been developed, basically from scratch as earlier consultation or survey research on BPM implementation in The Netherlands is scarce or omitting. To enable a field consultation on the potential definitions and implementation approaches for BPM and BPM-systems, the survey had a broad scope and consisted of several parts. The survey structure was:

- General questions. Some open questions concerning the respondent's role, type of company, number of employees, industry.

- Questions on the definition of BPM. Two definitions were provided, as well as six Likert-items related to BPM and BPM-systems.

- Questions on the perspectives for BPM. Some open questions on models and tools used in relation to different BPM-perspectives, i.e. the strategic, operational, design, change perspective, etc.

- Questions on the architecture for BPM. Some closed and open questions concerning the software architecture of a BPM-systems.

- Questions on the implementation of BPM-systems. In total 26 Likert-items related to BPMsystems implementation (and its CSFs).

- Questions on competencies for BPM. Some open questions about the knowledge, skills and attitude required for BPM(-system) implementations.

The original questions and items will be described in detail in the next sections, as for this paper, we mainly focus on the questions that were answered on the definition and implementation of BPM-systems. The complete questionnaire (in Dutch) is available upon request.

The survey was sent out to the contact persons of in total 925 organizations based in The Netherlands. These organizations were divided in two groups: a first group of 700 companies were member of the Dutch "BPM Forum", a second group consisted of 225 companies whose managers follow professional courses at the University of Applied Sciences Utrecht. This division enabled us to recruit both companies with a (relatively) high and lower of knowledge on BPM. The BPM forum members are assumed to have a different view on the BPM-domain compared to the second group of companies. As stated above, the sample was also specifically stratified to recruit respondents from:

1. developers of software tools for BPM-systems;

2. consultancy organizations; and

3. end-user organizations.

\section{[TABLE 1]}

The survey was provided through a personal e-mail with a link to a web questionnaire tool, to ease its completion and processing. Two reminders were sent out during the field work. Of the first group six email addresses turned out to be invalid and of the second group 23 people respondent that they did not have the level of knowledge that is needed to fill out the questionnaire. The final response consisted of 39 fully completed questionnaires. This response rate of 4.2 percent (or 6.7 percent including the 23 responses that did not fill out the questionnaire) is below expectations, but not exceptional for surveys among respondents that are not directly related or acquainted to the sender (Sivo et al., 2006; Grover et al., 1993). It should also be noted that the survey took a considerable time to complete the questionnaire, i.e. about 40 minutes.

Despite the limited size of the response group, we were able to achieve sufficient variation on two important criteria. As Table I shows, our respondents were equally divided over BPM forum membership and their professional role with regard to the BPM vale chain.

\section{The definition and benefits of BPM and BPM-system: a validation}

As stated earlier there are many different definitions for BPM and BPM-systems. It can therefore be expected that there is disagreement or confusion on what BPM is among different groups of practitioners. To find out whether this is the case, we proposed our stratified group of respondents the following definition of BPM, first as a management concept: 
Ravesteyn, P., Batenburg, R. Surveying the critical success factors of BPM-systems implementation. Business Process Management Journal: 2010, 16(3), 492-507

Business Process Management is "a field of knowledge at the intersection between Business and Information technology, encompassing methods, techniques and tools to analyze, improve, innovate, design, enact and control business processes involving customers, humans, organizations, applications, documents and other sources of information” (van der Aalst et al., 2003).

The respondents largely agreed with this description of the management concept BPM. On a seven-point scale (ranging from 1 - fully disagree with this definition until 7 - fully agree with this definition) the mean score was 5.15 with a standard deviation of 1.33 indicating a high level of consensus also. Differences between respondents by membership or professional BPM role (Table I) were small and non significant (two-tailed $t$-test).

Second, we proposed the following definition of BPM-systems, to explore the opinions on the IS/IT technology of BPM implementation:

Business Process Management Systems is "as a (suite of) software application(s) that enable the modeling, execution, technical and operational monitoring, and user representation of business processes and rules, based on integration of both existing and new information systems functionality that is orchestrated and integrated via services” (Ravesteyn and Versendaal, 2007).

\section{[TABLE 2]}

Again, the 39 respondents largely agreed with this definition; mean score is 5.0 and standard deviation is 1.47. Also, differences between the respondent groups were small and non significant.

We can conclude that a potential discussion or disagreement about the definition of BPM and BPMsystems is not recognizable from the two survey questions analyzed. An open question to comment on the two definitions was not used by the respondents at all, which supports this conclusion.

Based on these definitions, we subsequently asked respondents to rate six items on BPM and BPMsystems on a seven-point Likert scale. The items presented in Table II (translated from the original Dutch version) are formulated to measure how innovative and promising the respondents believe BPM is. The items originate from a meta-analysis of BPM literature (Ravesteyn, 2007a). Note that items 3 and 4 are formulated deviant from the others, to place variation within the item list and trigger respondents to carefully read and answer the different statements. Item 1 refers to a figure presented to the respondents that shows a brief historical overview of how BPMS evolved from different management concepts and IT innovations during the past two decades. Current BPM-systems aim at supporting the different management concepts by offering an integrated suite of functionality that is based on IT developments such as WFM and integration capabilities. In itself, a BPM-system is not meant to replace existing (legacy) systems in an organization. Instead, it uses the information in these systems and adds a new process and integration layer to make the entire information system more flexible and adaptable so the business is able to be more agile. The figure presented in the questionnaire is shown in Figure 1.

\section{[FIGURE 1]}

On average, respondents agreed with all statements as averages are 4.0 or higher (on a similar seven-point agreement scale as presented above). So the formulated innovative and adaptive potentials of BPM are recognized, although some were more supported than others. Flexibility and adaption to change was agreed upon most prominently (average 5.3) while the newness of BPM-systems was less supported. For all statements standard deviations are relatively low, indicating consensus within the group of respondents, while no significant differences between the respondents groups were found either (Table III).

Based on these results, we tested the interrelations and (one-dimensional) consistency of the set of items by applying exploratory factor analysis. It appears that the six items load on two factors (eigenvalue are 2.48 and 1.58, respectively, cumulative explained variance is 68 percent). As could be expected, the first factor consists of the four items (no. 1, 2, 5 and 6) that are "positively" oriented towards BPM, while the second (no. 2 and 3) comprehends the two critically formulated items.

A Cronbach's of 0.77 proofs reliability of the first four-item scale, while the two items of the second dimension significantly correlate as well $(r=+0.43, p=0.00)$.

[TABLE 3 AND TABLE 4]

Further analysis is conducted on the differences between the subgroups within our sample, i.e. BPM forum membership and the professional BPM role of the respondent. As can be seen from Table IV, between- 
group differences exist but in most cases these were not significant. On item 6, the BPM forum members agreed highly (5.62), while the average for non-members was moderate (4.73). A (two-sided) $t$-test for independent groups (significance level $p<0.05$ ) supported that this difference was significant. Also, statement 1 (that refers to Figure 1) was rated higher by the end-user organizations (5.67) than by the developers and consultancy organizations (a mean of, respectively, 4.33 and 4.05). From ANOVA-analysis however, it appears that these differences are non-significant. It is worth noting though, that the BPM forum members commented more frequently on how to improve this figure while there were no comments whatsoever by the non-member group.

\section{The CSFs for BPM-system implementation: a framework}

Now that we have found that the most-mentioned definitions and benefits of BPM and BPM-systems (which were derived from an earlier meta-analysis of literature, Ravesteyn, 2007a) are confirmed by our respondents, we take the next step to investigate their opinions about the CSFs for implementing BPMsystems. In order to identify the most important CSFs of BPMS implementation, another literature study (Ravesteyn, 2007a) of 104 articles and books was performed. For each article or book, the domain and type of research approach was coded and classified. The different domain categories are based on the two evolutionary drivers behind BPMSs, i.e. TQM, BPR, WFM, enterprise application integration, business activity monitoring, and others (see Figure 1 shown in the previous section). Next to this, CSFs were classified according to the CSFs that are knowns from ERP implementations (Hong and Kim, 2002; Bradford and Florin, 2003; Kamhawi, 2007). Combining both classifications, we see that CSFs that are specific to the implementation of a BPMS typically relate to the development and use of services, together with data about granularity of services, integration of existing applications via services, and data quality. Together, with its categorization, a long list was compiled with over 337 different CSFs. From this list, the CSFs were selected that were found three or more times in the literature base. This reduced the total number of factors to 55 prominent CSFs for BPMS implementations.

\section{[FIGURE 2]}

The 55 CSFs were then categorized in two ways. First into a business or IT domain, based on the principles of strategic and business/IT alignment (Henderson and Venkatraman, 1993; Luftman, 2000). Second, they were allocated along the three main dimensions of BPMS projects:

1. management and organization;

2. architecture; and

3. IT integration.

Jointly, the CSFs can be clustered into five areas of BPMS implementation, that build a BPMS implementation framework:

1. the ongoing domain of the business organization itself;

2. the measurement and control function within the organizational domain;

3. the BPMS implementation project domain;

4. architectural issues within the project domain; and

5. development activities within the project domain.

This framework is shown in Figure 2. It shows the areas that are assumed to be a crucial part of a BPMS implementation methodology. It also depicts that a BPMS implementation is a continuous process to go from the "as is" to the "to be" situation through different project steps.

The framework in Figure 2 shows that the BPMS implementation project domain consists of two phases, the "architecture design" phase and the "development phase." In the first phase, a process and information architecture should be developed, i.e. the BPM part. Subsequently, this can be used in the realization of the technical infrastructure and creation of service-oriented business applications, both part of the second phase. The two phases, that are part of any BPMS project, are supported by project and change management simultaneously. Applying the BPM and SOA paradigm both imply that changes in processes and IT-applications occur while working on a project. The BPM-system implementation can be regarded as a project or series of small projects, while the organization, the measurement and control function are in fact just a small part of the project.

In applying the BPMS implementation framework, it should be noted that in most cases, an organization that wants to implement BPMS will already have an standing organization structure with running processes, which will be the starting point ("as is") for the implementation. Likewise, any organization that is already 
in operation will have some type of measurement and control function. For small businesses, this will probably be the accounting function only. For medium and large organizations, other functions will provide information about the organization and processes, such as the quality department, etc. To succeed in implementing BPMS, there should be sufficient measurement information available about the processes that are going to be modeled. If this is not the case, the assumption behind the framework is violated and the implementation should not be started. Metrics on processes are therefore important to be able to continuously measure the effects of any changes.

Based on the BPMS implementation framework and the CSFs found through the literature study and metaanalysis a list of 26 statements was constructed to use the respondents for validation. We confronted the respondents with a list of Likert-items and asked them to indicate if they agreed to the statements, i.e. to rank if the CSF at stake is indeed relevant as suggested by literature and our BPMS implementation framework. Table V shows the answers of our 39 respondents on the items that are ordered according to the five areas of the framework.

From Table V, we see that item 25: "Communication throughout the entire BPMS project is a crucial factor to succeeding" holds the highest mean value (6.69). Other items that are very much agreed upon are items 2, 5 and 6. Items 2 and 5 are about involving the right people in the project and making sure that there is support from top management. Item 6 is governance-related and fits with the current attention for the business/IT governance issues as for example in Committee of Sponsoring Organizations and Cobit (ITGI, 2006). Item 3, which states that BPMS should be a mandatory part of an organizations strategy, is rated lowest (3.41) but its standard deviation is also relatively high. The same applies for items 1 and 21.

If we oversee the complete set of items, most statements were agreed upon by the respondents (average as 3.97 on a seven-point scale) with a relative high level of consensus (i.e. low standard deviations). We performed scale analysis to explore the one-dimensionality of the set of 16 items. This resulted in a Cronbach's alpha of 0.781, showing that all items are relevant indicators of the BPMS implementation framework.

In a second step of analysis, we determine if the different groups we used for sample stratification rated the 26 items differently. As in the previous section, $t$-tests were performed to see if there were statistical significant differences between the BPM forum members and the other group. The result was that we did not found any significant difference between the two groups rated the items in Table V. In addition, we tested the distances between the answers of respondents from (BPM) developers, consultancy and end-user organizations. In three cases, ANOVA-analysis showed significant differences between three groups. Respondents from the developers rated items 4 and 12 significantly higher as the respondents from the other two groups, while the developers' respondents also rated item 8 significantly lower than the consultancy and end-user respondents. So the items "the implementation of BPMS should be aligned to the organizations strategy" and "in the BPMS implementation we used information from existing information systems and databases" was particularly agreed upon by the developers group, while the item "in the modeling phase of a BPMS implementation project it is possible to use any modeling standard or technique" was strongly disagreed by respondents from the developers group. With regard to these items the respondents from the consultant and end-user organizations do not differ in their opinion.

\section{[TABLE 5]}

\section{Conclusions}

In this paper, we presented the results of a survey among a group of 39 Dutch consultants, developers and end-users on how they view the concept of BPM, BPM-systems and its CSFs for implementation. The three groups were randomly selected from two separate populations with a high and low level of knowledge about BPM. A first interesting result is that these different groups mostly share a common view on BPM and BPM-systems, regardless their role in the value chain of BPM deployment within organizations. Distinctive is, that developers and consultants with a specific BPM-experience more strongly believe that applying BPM enables organizations to improve processes and IS/IT in a more flexible and adaptive way. This outcome can be understood from the fact that these respondents are actually involved with the design and deployment of BPM-systems.

Through a list of 26 items the survey also validated that our BPMS implementation framework has a strong internal coherence and covers the main CSFs that have to be considered when implementing a BPMS. Most prominently supported by the respondents are the CSFs regarding communication, 
involvement of stakeholders and governance. This is expressed by the high agreement on statements as "Communication throughout the entire BPMS project is a crucial factor to succeeding", items with regard to the level of support from top management, making governance one of the project goals and involving the right people during the project. In this analysis, the different respondent groups agreed largely to the same extent on the items, although developers seemed to have a stronger opinion on some items. This group most strongly agreed with the statements that aligning software tools to the organizations strategy, and reusing existing information systems and applications when implementing BPMS is of high importance.

From a normative perspective (but based on our survey results), we suggest that organizations that start implementing BPMS should realize that it is not mainly an IT-project. A BPMS should support the goals of the business and therefore this BPMS projects are of strategic importance. They should preferably be initiated by top management within the organization, although small bottom up BPMS projects could function as a "built up experience." The CSFs as validated by our survey basically advocate that no major BPMS projects should be under taken without a top down approach.

\section{Discussion and future research}

Some important limitations should be recognized with regard to the results of this research. Most prominent, the results are limited to The Netherlands, i.e. the views of Dutch BPM practitioners. An obvious extension of this research is to apply the survey within other countries, and to subsequently explore the validity of our BPM definitions, implementation framework and accompanied item list. A very interesting step for further research is to see if the definition of the BPM-domain differs between countries and/or cultural regions. This could be specifically investigated by surveying enterprises with international locations.

A second point of extension is in the practical usability of the BPM implementation framework. A profound claim to be tested is to see from case or project studies whether applying the framework actually improves the success of BPM-projects and BPM-system implementations. The question here, in other words, is about the added value of the framework and the extend to which it needs more or less level of detail. Currently, the framework is theory based, while a next step needs to be set to support the actual project management of BPM(-system) implementations.

\section{REFERENCES}

Al-Mashari, M., Irani, Z., Zairi, M. (2001), "Business process reengineering: a survey of international experience", Business Process Management Journal, Vol. 7 No.5, pp.437-55.

Bhatt, G.D., Trout, M.D. (2005), "Examining the relationship between business process improvement initiatives, information systems integration and customer focus: an empirical study", Business Process Management Journal, Vol. 11 No.5, pp.532-58.

Bradford, M., Florin, J. (2003), "Examining the role of innovation diffusion factors on the implementation success of enterprise resource planning systems", International Journal of Accounting Information Systems, Vol. 4 No.3, pp.205-25.

Crowe, T.J., Fong, P.M., Bauman, T.A., Zayas-Castro, J.L. (2002), "Quantitative risk level estimation of business process reengineering efforts", Business Process Management Journal, Vol. 8 No.5, pp.490511.

Davenport, T.H., Harris, J.G., Cantrell, S. (2004), "Enterprise systems and ongoing process change", Business Process Management Journal, Vol. 10 No.1, pp.16-26.

Davis, E., Spekman, R. (2003), The Extended Enterprise: Gaining Competitive Advantage through

Collaborative Supply Chains, Financial Times Prentice-Hall, Upper Saddle River, NJ, .

Deming, W.E. (1982), Quality, Productivity, and Competitive Position, MIT Press, Cambridge, MA, MIT Center for Advanced Engineering Study, .

Fremantle, P., Weerawarana, S., Khalaf, R. (2002), "Enterprise services: examining the emerging field of web services and how it is integrated into existing enterprise infrastructures", Communication of the ACM, Vol. 45 No.10, pp.77-82.

Grover, V., Lee, C.C., Durand, D. (1993), "Analyzing methodological rigor of MIS survey research from 1980-1989", Information \& Management, Vol. 24 No.6, pp.305-17.

Hammer, M. (2007), "The process audit", Harvard Business Review, No.April, .

Hammer, M., Champy, J. (2001), Reengineering the Corporation: A Manifesto for Business Revolution, updated and revised edition, Harper Business, New York, NY, .

Harmon, P. (2004), "Evaluating an organisation's business process maturity", Business Process Trends, Vol. March. 
Ravesteyn, P., Batenburg, R. Surveying the critical success factors of BPM-systems implementation. Business Process Management Journal: 2010, 16(3), 492-507

Henderson, J.C., Venkatraman, N. (1993), "Strategic alignment: leveraging information technology for transforming organizations", IBM Systems Journal, Vol. 32 No.1, pp.4-16.

Hill, J.B., Sinur, J., Flint, D., Melenovsky, M.J. (2006), Gartner's Position on Business Process Management, Gartner, Stamford, .

Hong, K.K., Kim, Y.G. (2002), "The critical success factors for ERP implementation: an organizational fit perspective", Information \& Management, Vol. 40 No.1, pp.25-40.

ITGI (2006), Enterprise Value: Governance of IT Investments (The Val IT Framework), The IT Governance Institute, Rolling Meadows, IL, .

Kamhawi, E.M. (2007), "Critical factors for implementation success of ERP systems: an empirical investigation from Bahrain", International Journal of Enterprise Information Systems, Vol. 3 No.2, pp.3449.

Karagiannis, D. (1995), "BPMS: business process management systems", SIGIOS Bull, Vol. 16 No.1, pp.10-13.

Kim, Y., Lee, Z., Gosain, S. (2005), "Impediments to successful ERP implementation process", Business Process Management Journal, Vol. 11 No.2, pp.158-70.

Krafzig, D., Banke, K., Slama, D. (2004), Enterprise SOA: Service Oriented Architecture Best Practices, Prentice-Hall PTR, Upper Saddle River, NJ, .

Lee, C., Lee, G., Lin, H. (2007), "The role of organizational capabilities in successful e-business implementation", Business Process Management Journal, Vol. 13 No.5, pp.677-93.

Lee, J., Lee, D., Kang, S. (2007), "An overview of the business process maturity model (BPMM)", APWeb/WAIM 2007 Ws, LNCS 4537, pp.384-95.

Luftman, J. (2000), "Assessing business - IT alignment maturity", Communications of the Association for Information Systems, Vol. 4 pp.1-49.

Mansar, L.S., Reijers, H.A. (2007), "Best practices in business process redesign: use and impact", Business Process Management Journal, Vol. 13 No.2, pp.193-213.

Osuagqu, L. (2002), "TQM strategies in developing economy: empirical evidence from Nigerian companies", Business Process Management Journal, Vol. 8 No.2, pp.140-60.

Ravesteyn, J.P.P. (2007a), "A study into the critical success factors when implementing business process management systems", paper presented at International Resources Management Association, Vancouver, .

Ravesteyn, J.P.P. (2007b), "Business process management systems: hype or new paradigm", paper presented at International Information Management Association, Beijing, October, .

Ravesteyn, J.P.P., Versendaal, J. (2007), "Success factors of business process management systems implementation", paper presented at Australasian Conference on Information Systems, Toowoomba, December, .

Rosemann, M., de Bruin, T. (2005), "Towards a business process management maturity model", Proceedings of the 13th European Conference on Information Systems (ECIS 2005), Regensburg, Germany, May 26-28,

Rosemann, M., de Bruin, T., Hueffner, T. (2004), "A model for business process management maturity", Conference Proceedings of ACIS 2004,

Shaw, D.R., Holland, P., Kawalek, P., Snowdon, B., Warboys, B. (2007), "Elements of a business process management system: theory and practice", Business Process Management Journal, Vol. 13 No.1, pp.91107.

Sivo, S.A., Saunders, C., Chang, Q., Jiang, J.J. (2006), "How low should you go? Low response rates and the validity of inference in IS questionnaire research", Journal of the Association for Information Systems, Vol. 7 No.6, .

Smith, H., Fingar, P. (2003), Business Process Management: The Third Wave, 1st ed., Meghan-Kiffer Press, Tampa, FL, .

van der Aalst, W.M.P., ter Hofstede, A.H.M., Weske, M. (2003), "Business process management: a survey", paper presented at Business Process Management, Eindhoven, .

Wells, M.G. (2000), "Business process re-engineering implementations using internet technology",

Business Process Management Journal, Vol. 6 No.2, pp.164-84.

Weske, M., van der Aalst, W.M.P., Verbeek, H.M.W. (2004), "Advances in business process management", Data \& Knowledge Engineering, Vol. 50 pp.1-8.

Woon, K. (2000), "Assessment of TQM implementation: benchmarking Singapore's productivity leaders", Business Process Management Journal, Vol. 6 No.4, pp.314-30.

Further Reading

Nunnally, J. (1979), Psychometric Theory, McGraw-Hill, New York, NY, .

Peter, J.P. (1979), "Reliability: a review of psychometric basics and recent marketing practices", Journal of Marketing Research, Vol. 16 pp.6-17. 
Ravesteyn, P., Batenburg, R. Surveying the critical success factors of BPM-systems implementation. Business Process Management Journal: 2010, 16(3), 492-507

\section{FIGURES AND TABLES}

Table I: The survey response group by membership of the BPM forum and BPM supply chain position

\begin{tabular}{lcccc}
\hline & & \multicolumn{2}{c}{ Professional BPM position } & \\
& BPM developer & BPM consultant & BPM end-user & Total \\
\hline Member of the BPM forum & 6 & 15 & 3 & 24 \\
None BPM forum member & 0 & 6 & 9 & 15 \\
Total & 6 & 21 & 12 & 39
\end{tabular}

Table II. Judgment of the statements on BPM and BPM-systems

\begin{tabular}{|c|c|c|c|}
\hline No. & Item & Mean & SD \\
\hline 1 & $\begin{array}{l}\text { Figure } 1 \text { (see text above this table) shows how, } \\
\text { according to us, management concepts and IT } \\
\text { innovations have evolved into BPM-systems }\end{array}$ & 4.58 & 1.58 \\
\hline 2 & $\begin{array}{l}\text { The BPM-systems that are currently on the market } \\
\text { can be considered a new type of software application }\end{array}$ & 4.07 & 1.75 \\
\hline 3 & $\begin{array}{l}\mathrm{BPM} \text { is being hyped as a new management concept } \\
\text { but it has been around for a long time and can } \\
\text { therefore not be considered as new }\end{array}$ & 4.18 & 1.62 \\
\hline 4 & $\begin{array}{l}\text { BPM-systems are nothing more than a combination } \\
\text { of long existing IT applications and functionality }\end{array}$ & 4.15 & 1.59 \\
\hline 5 & $\begin{array}{l}\text { The essence of BPM is the continuous measuring } \\
\text { and improving of operational processes }\end{array}$ & 4.79 & 1.79 \\
\hline 6 & $\begin{array}{l}\text { By applying BPM an organization is able to make its } \\
\text { processes and supporting information systems more } \\
\text { flexible and adaptive to change }\end{array}$ & 5.28 & 1.29 \\
\hline
\end{tabular}


Figure 1. Historical roadmap to BPMS

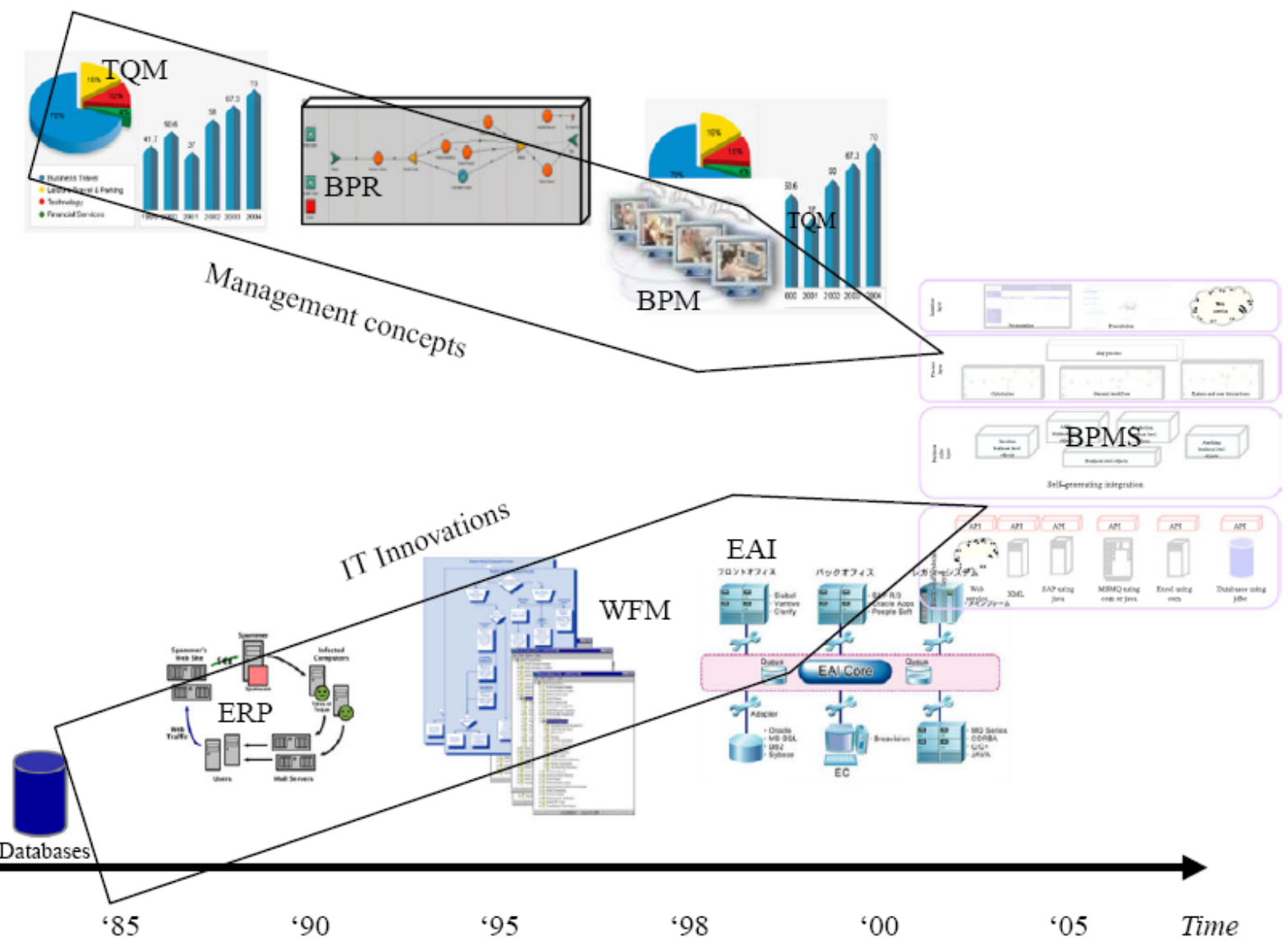

Table III.Factor analysis results (after varimax rotation) on six statements on BPM and BPM-systems

\begin{tabular}{llll}
\hline No. & Item & Factor 1 & Factor 2 \\
\hline 1 & $\begin{array}{l}\text { Figure 1 (see text above this table) shows how, } \\
\text { according to us, management concepts and IT } \\
\text { innovations have evolved into BPM-systems } \\
\text { The BPM-systems that are currently on the market } \\
\text { can be considered a new type of software application } \\
\text { The essence of BPM is the continuous measuring } \\
\text { and improving of operational processes }\end{array}$ & 0.78 & -0.09 \\
5 & $\begin{array}{l}\text { By applying BPM an organization is able to make its } \\
\text { processes and supporting information systems more } \\
\text { flexible and adaptive to change }\end{array}$ & 0.84 & -0.46 \\
& $\begin{array}{l}\text { BPM is being hyped as a new management concept } \\
\text { but it has been around for a long time and can } \\
\text { therefore not be considered as new } \\
\text { BPM-systems are nothing more than a combination } \\
\text { of long existing IT applications and functionality }\end{array}$ & 0.64 & 0.01 \\
4 & & 0.13 & 0.76
\end{tabular}


Table IV. Factor scores on the six statements on BPM and BPM-systems

\begin{tabular}{|c|c|c|c|c|c|c|c|c|}
\hline \multirow[b]{2}{*}{ No. } & \multirow[b]{2}{*}{ Item } & \multicolumn{3}{|c|}{$\begin{array}{l}\text { BPM forum } \\
\text { member }\end{array}$} & \multirow[b]{2}{*}{ Consultant } & \multicolumn{3}{|c|}{$\begin{array}{l}\text { Professional BPM } \\
\text { position } \\
\text { End- }\end{array}$} \\
\hline & & No & Yes & Diff. & & Developer & user & Diff. \\
\hline 1 & $\begin{array}{l}\text { Figure } 1 \text { (see text above this table) } \\
\text { shows how, according to us, } \\
\text { management concepts and IT } \\
\text { innovations have evolved into BPM- } \\
\text { systems }\end{array}$ & 4.46 & 4.80 & ns & 4.05 & 4.33 & 5.67 & Sig.* \\
\hline 2 & $\begin{array}{l}\text { The BPM-systems that are currently } \\
\text { on the market can be } \\
\text { considered a new type of software } \\
\text { application }\end{array}$ & 4.27 & 3.96 & ns & 3.95 & 4.17 & 4.25 & ns \\
\hline 3 & $\begin{array}{l}\text { BPM is being hyped as a new } \\
\text { management concept but it has been } \\
\text { around for a long time and can } \\
\text { therefore not be considered as new }\end{array}$ & 4.60 & 3.92 & $\mathrm{~ns}$ & 4.05 & 4.00 & 4.50 & ns \\
\hline 4 & $\begin{array}{l}\text { BPM-systems are nothing more } \\
\text { than a combination of long existing }\end{array}$ & & & & & & & \\
\hline & IT applications and functionality & 4.27 & 4.08 & ns & 4.33 & 3.50 & 4.17 & ns \\
\hline 5 & $\begin{array}{l}\text { The essence of BPM is the } \\
\text { continuous measuring and } \\
\text { improving of operational processes }\end{array}$ & 5.47 & 4.38 & ns & 4.48 & 4.67 & 5.42 & ns \\
\hline 6 & $\begin{array}{l}\text { By applying BPM an organization } \\
\text { is able to make its processes and } \\
\text { supporting information systems } \\
\text { more flexible and adaptive to } \\
\text { change }\end{array}$ & 4.73 & 5.62 & Sig.* & 5.33 & 6.17 & 4.75 & $\mathrm{~ns}$ \\
\hline
\end{tabular}

Notes: *Significant based on two-sided $t$-test $(t=2.13, \mathrm{df}=37$, sig. $=0.35) ; *$ significant based on $F$-test $(F=4.92, \mathrm{df}=36$, sig. $=0.31)$

Figure 2. BPMS implementation framework

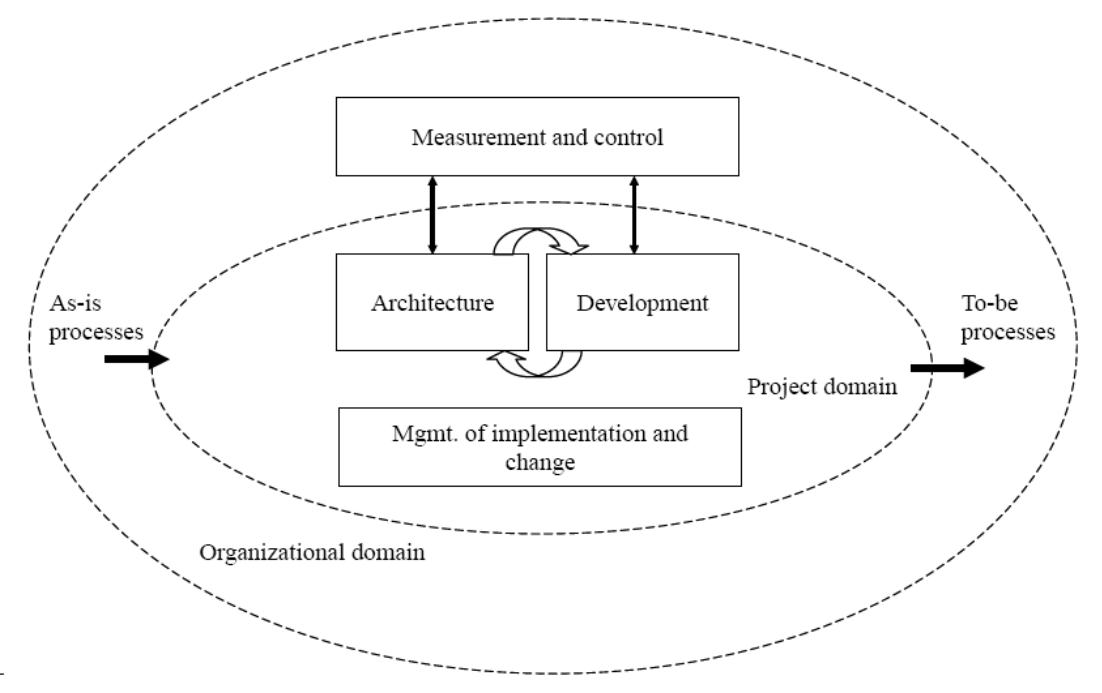




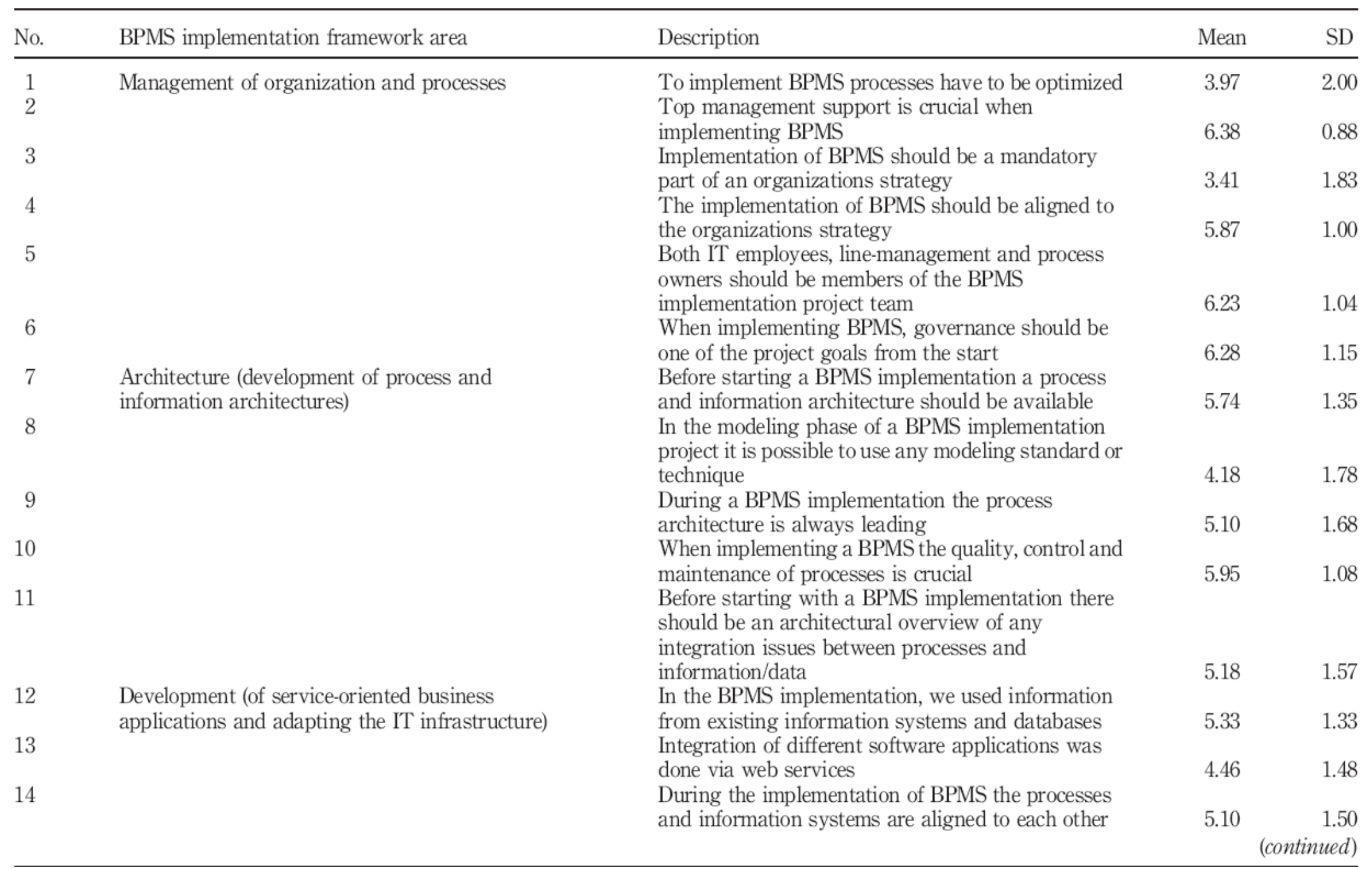




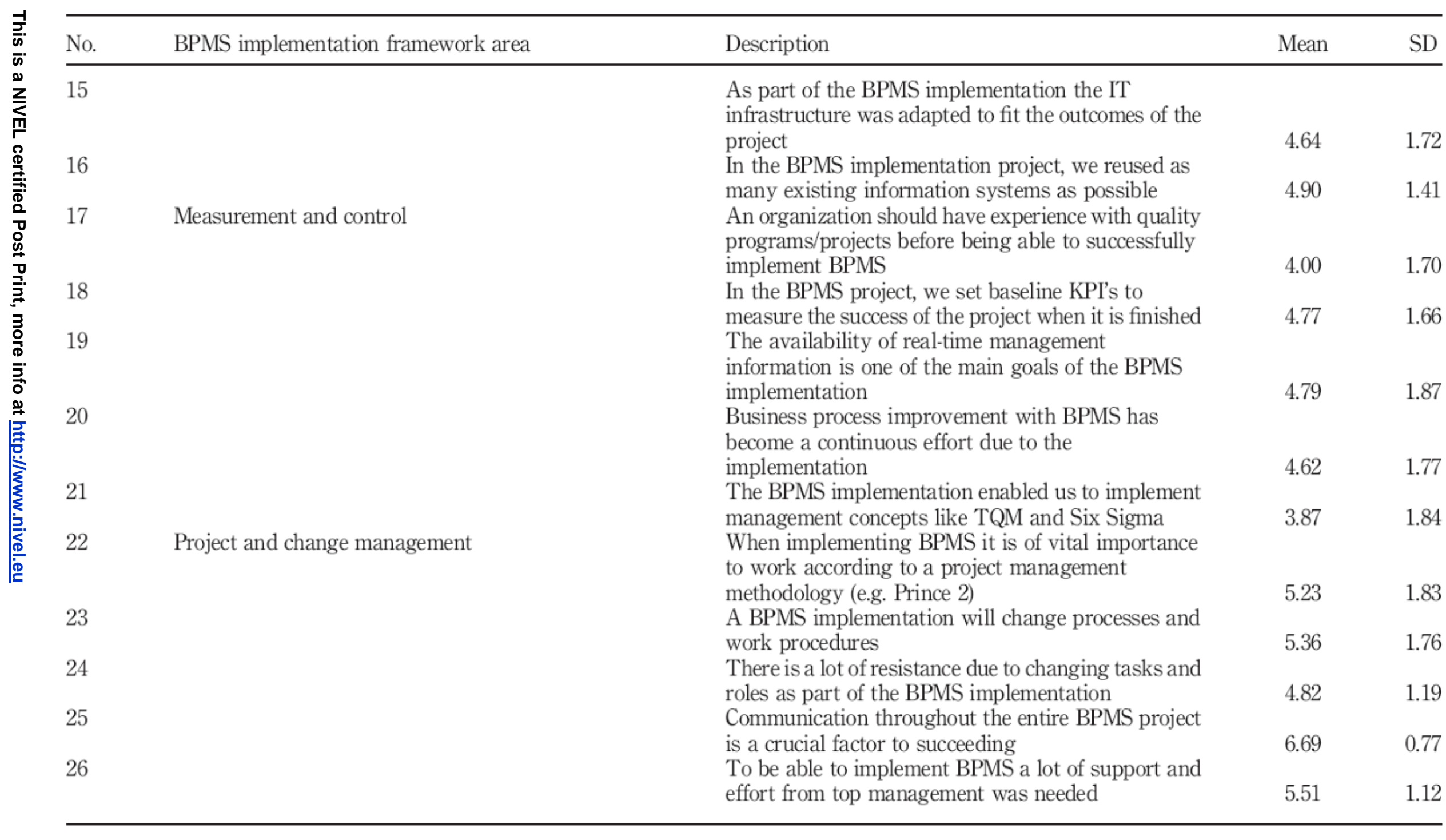

